\title{
Anticorpos Anti-Gangliosídeos em Pacientes com Síndrome de Guillain-Barré Associado à Infecção pelo Vírus Zika no Brasil
}

\author{
Anti-Ganglioside Antibodies in Patients with Zika Virus Infection- \\ Associated Guillain-Barré Syndrome in Brazil
}

\author{
Mateus do Rosário ${ }^{1,2}$ \\ ${ }^{1}$ Serviço de Neurologia do Hospital Santa Izabel; ${ }^{2}$ Universidade do Estado da Bahia;
} Salvador, Bahia, Brasil

Correspondence addresses:

Mateus do Rosário

drmateusan@gmail.com

Received: October 24, 2019

Revised: October 30, 2019

Accepted: October 30, 2019

Published: December 2 ${ }^{\text {nd }}, 2019$

Data Availability Statement: All relevant data are within the paper and its Supporting Information files.

Funding: This work was the result of author's initiative. There was no support of research or publication funds.

Competing interests: The author has declared that no competing interests exist.

\section{Copyright}

(C) 2019 by Santa Casa de Misericórdia da Bahia.

All rights reserved.

ISSN: 2526-5563
A infecção pelo vírus zika está associada ao desenvolvimento da Síndrome de Guillain-Barré (SGB), uma doença autoimune neurológica causada pelo reconhecimento imune de gangliosídeos e outros componentes nas membranas das células neuronais. Utilizando ELISA de alto rendimento, analisamos o perfil de anticorpos anti-glicolipídeos, incluindo gangliosídeos, de amostras de plasma de pacientes com infecções por zika associadas ou não à SGB em Salvador, Bahia, Brasil. Observamos que os pacientes infectados com o zika vírus que desenvolvem SGB apresentam níveis mais altos de anticorpos antigangliosídeos quando comparados com pacientes infectados com zika sem SGB. Também observamos que um amplo repertório de gangliosídeos foi direcionado por auto anticorpos anti IgM e IgG nesses pacientes. Como o vírus zika infecta neurônios, que contêm gangliosídeos de membrana, a apresentação antigênica dessas células infectadas pode estimular os autoanticorpos anti-gangliosídeos observados, sugerindo que os autoanticorpos induzidos diretamente pela infecção podem levar ao desenvolvimento de SGB. Nossos resultados estabelecem, coletivamente, uma ligação entre anticorpos antigangliosídeos e SGB associado ao zika vírus.

Palavras-chave: Zika; Autoanticorpos; Anti-Gangliosídeos; Síndrome de Guillain-Barré.

Zika virus infection is associated with the development of Guillain-Barré Syndrome (GBS), a neurological autoimmune disorder caused by immune recognition of gangliosides and other components at nerve membranes. Using a high-throughput ELISA, we have analyzed the anti-glycolipid antibody profile, including gangliosides, of plasma samples from patients with zika infections associated or not with GBS in Salvador, Brazil. We have observed that zika patients that develop GBS present higher levels of anti-ganglioside antibodies when compared to zika patients without GBS. We also observed that a broad repertoire of gangliosides was targeted by both IgM and IgG anti-self antibodies in these patients. Since zika virus infects neurons, which contain membrane gangliosides, antigen presentation of these infected cells may trigger the observed autoimmune anti-ganglioside antibodies

Resumo do Artigo: Rivera-Correa J, de Siqueira IC, Mota S, do Rosário MS, Pereira de Jesus PA, Alcantara LCJ, et al. Anti-ganglioside antibodies in patients with zika virus infectionassociated Guillain-Barré Syndrome in Brazil. PLoS Negl Trop Dis. 2019;13(9):e0007695. https://doi.org/10.1371/journal.pntd.0007695. 
suggesting direct infection-induced autoantibodies as a cause leading to GBS development. Collectively, our results establish a link between anti-ganglioside antibodies and Zika-associated GBS in patients.

Keywords: Zika; Antibodies; Anti-Ganglioside; Guillain-Barré Syndrome.

\section{Introdução}

O vírus zika é um arbovírus da família Flaviviridae, que, como o dengue e o alfavirus chikungunya são transmitidos pelo mosquito Aedes. Embora descoberto em 1947 em Uganda, o primeiro grande surto de vírus zika foi relatado na Micronésia em 2007, ${ }^{1}$ seguido pelo surto da Polinésia Francesa em $2014^{2}$ e o enorme surto na América Latina em 2015, que foi relatado pela primeira vez no Brasil e se espalhou pelas Américas. ${ }^{3}$ Durante esse surto, complicações alarmantes associadas ao zika, como microcefalia e Síndrome de GuillainBarré (SGB) foram relatadas. ${ }^{4}$

A SGB é uma neuropatia inflamatória e a causa mais comum de paralisia neuromuscular no mundo, ${ }^{5} \mathrm{~A}$ etiologia da SGB é desconhecida, mas seu desenvolvimento tem sido altamente associado a respostas autoimunes pósinfecciosas contra gangliosídeos nos nervos periféricos.

Gangliosídeos são glicosfingolipídeos encontrados nas membranas neuronais e estão envolvidos em diferentes funções neuronais. Anticorpos autoimunes que reconhecem gangliosídeos são encontrados em uma grande proporção de pacientes com SGB (62\%) e acredita-se que contribuam para a patologia final, induzindo lesão axonal mediada por complemento e desmielinização. ${ }^{6}$ Mimetismo molecular foi proposto como um mecanismo provável de SGB induzido por infecção, em que os anticorpos gerados contra antígenos microbianos com semelhanças estruturais com gangliosídeos específicos reagem de forma cruzada com gangliosídeos do hospedeiro nas membranas neuronais. Um exemplo clássico é a SGB associada com infecção por Campylobacter jejuni. ${ }^{6} \mathrm{O}$ vírus zika foi adicionado à lista de patógenos associados à
SGB devido à alta incidência relatada durante o surto na América Latina de 2015. No entanto, a SGB associada ao vírus zika mostra anticorpos anti-gangliosídeos (anti-GA1) que não podem ser atribuídos ao mecanismo de mimetismo molecular, ${ }^{5}$ tal como descrito pela infecção pelo C. jejuni, sugerindo mecanismos alternativos para a geração de autoanticorpos como resultado da infecção pelo zika.

Em muitos distúrbios autoimunes, como a artrite reumatoide, os autoanticorpos desempenham um importante papel patológico no desenvolvimento da doença. Curiosamente, o aumento dos níveis de anticorpos IgG contra o gangliosídeo GD3 foram observados em pacientes com infecção aguda por zika sem manifestações neurológicas como SGB. ${ }^{7}$ Algumas manifestações clínicas de SGB foram associadas a níveis elevados de autoanticorpos, como anticorpos anti-gangliosídeos que podem atingir os nervos periféricos, mas a associação desses anticorpos com a SGB relacionada ao Zika ainda permanece incerto.

Neste estudo, avaliamos os níveis de reatividade de anticorpos contra 17 glicolipídios diferentes, incluindo principalmente gangliosídeos, apresentados em forma única e combinada, no plasma de pacientes infectados com Zika de um dos locais do surto de 2015 em Salvador, Bahia, Brasil. ${ }^{7}$ Observamos que os pacientes com SGB associado ao Zika apresentam níveis significativamente mais altos de glicolipídeos em comparação com pacientes infectados com Zika que não tinham SGB. Também observamos um amplo repertório de glicolipídios, incluindo gangliosídeos, que foram alvos de anticorpos IgM e IgG. Em conjunto, esses resultados estabeleceram uma ligação entre anticorpos anti-gangliosídeos e pacientes com SGB associada ao zika vírus. 


\section{Métodos}

Desenho do Estudo e Coleta de Amostras

Casos de SGB e encefalite associados à infecção por arbovírus e infecção por zika sem sintomas neurológicos foram incluídos em um estudo de vigilância em unidades neurológicas de dois hospitais de referência em Salvador, Bahia, Brasil, de maio de 2015 a abril de 2016, durante o surto de zika nesta área. A população do estudo era de pacientes com síndrome neurológica aguda admitidos nos setores de neurologia dos hospitais participantes. Pacientes com infecções por zika, sem sinais de doença neurológica foram recrutados como parte de um programa de vigilância para infecções por zika nos mesmos hospitais. Todos os pacientes com síndromes neurológicas foram avaliados pelo neurologista pesquisador e o diagnóstico de SGB foi estabelecido de acordo com critérios internacionais. Os critérios de inclusão foram: (1) pacientes com sintomas compatíveis com SGB e suas variantes ou encefalite. O diagnóstico de SGB, síndrome de Miller-Fisher (SMF) e suas diversas variantes; e encefalite foi pré-determinado por critérios específicos da doença; (2) Pacientes que relataram doença exantematosa aguda ou febre nas 4 semanas antes do início dos sintomas neurológicos. Estudos de eletromiografia e condução nervosa foram realizados em pacientes com SGB.

\section{Análise Sorológica}

A detecção de anticorpos IgG anti-zika, anti-chikungunya e anti-dengue específicos $\mathrm{e}$ os anticorpos IgM dengue e anti-chikungunya foram realizados usando ELISA (Euroimmun, Lüberg, Alemanha), de acordo com o protocolo do fabricante. ELISA de captura de anticorpos IgM (MAC-ELISA), fornecido pela Divisão de Coleta de Referência de Arbovírus do CDC foi utilizado de acordo com o protocolo estabelecido. Detecção de RNA para o zika, chikungunya e dengue foram realizados por PCR por transcriptase reversa segundo métodos publicados. Amostras de pacientes positivas por neutralização da redução da placa do zika (PRNT) e / ou positivo para zika IgM e negativo para dengue IgM por ELISA (CDC) considerado positivo para a infecção pelo zika. O paciente 11 foi considerado positivo para infecção por zika porque mostrou IgG positivo para o zika e IgG negativo para a dengue. Somente no paciente 15, que positivou para IgG para zika e dengue, a reação cruzada não poderia ser descartada. A infecção pelo zika foi considerada aguda quando as amostras eram positivas para o RNA do zika por RT-PCR, e/ou zika IgM (por ELISA). Amostras biológicas, incluindo sangue, foram coletadas após admissão no hospital ou 4 meses após o início dos sintomas, quando indicado. $\mathrm{O}$ gerenciamento de dados foi realizado usando o REDCap 6.18.1 - 2018 Vanderbilt University.

\section{Gangliosídeo Gliosídeo}

Os lipídios utilizados foram: esfingomielina (SPM), fosfatidilserina (PS), sulfato (SULF), globosídeo(GS), tri-hexosilceramida(ácidograxo CTH-hidroxi), (THCH), Tri-hexosilceramida (ácido graxo não hidroxi-CTH) (THCHN), galactocerebrosídeo (GALC) e os gangliosídeos GM1, GM2, GM3, GA1, GD1A, GD1B, GD2, GD3, GT1Be GQ1B.

Cinco amostras diferentes de plasma (9b, 10a, 11, 14 e 16) de pacientes com SGB foram testados com cinco glicolipídios escolhidos aleatoriamente (SPM, GS, GM1, GD3 e SULF).

\section{Resultados}

A SGB relacionada ao zika é uma das complicações mais graves associadas a esta infecção. Nosso principal objetivo neste estudo é comparar a prevalência e as especificidades dos anticorpos anti-gangliosídeos em uma coorte de pacientes com SGB associados ao zika $(n=7) \mathrm{em}$ comparação com os infectados pelo zika sem SGB $(\mathrm{n}=8)$. Entre estes, alguns pacientes apresentaram encefalite $(n=3)$ ou foram infectados pelo zika sem sintomas neurológicos na fase aguda $(n=3)$ 
ou 4 meses após o início dos sintomas $(n=2)$. A mediana de dias entre o início dos sintomas virais e o início dos sintomas neurológicos foram de 10 dias para os pacientes com SGB associada ao zika.

Forte Resposta de Anticorpos AntiGangliosídeos em Pacientes com SGB Associada ao Zika

Foram analisadas a reatividade contra 17 lipídios, principalmente glicolipídios, incluindo gangliosídeos descritos como associados à SGB, sozinhos ou em 139 combinações em duplas. Primeiro, realizamos uma análise geral de todos os pacientes para determinar os níveis de reatividade gangliosídica em seu plasma usando um ELISA de alto rendimento para detectar anticorpos IgM e IgG anti-gangliosídeos. Esses ensaios mostraram reatividade anti-gangliosídeos aumentada no plasma de pacientes com SGB associada ao zika em comparação com pacientes com zika sem SGB (Figura 1A-1C). Coletivamente, esses resultados mostraram uma resposta aumentada de anticorpos gangliosídeos no plasma de pacientes com SGB associada ao zika em comparação com os controles.

Além disso, analisamos uma amostra de um paciente de SGB de etiologia desconhecida que tinha testes negativos para infecções por zika, dengue e chikungunya, e este mostrou um perfil semelhante aos pacientes zika-SGB.

Também analisamos o plasma de dois pacientes com SGB com infecção ativa pelo vírus chikungunya (IgM+) e infecção prévia pelo zika $(\mathrm{IgG}+)$. O plasma desses pacientes não apresentou forte reatividade contra gangliosídeos, em contraste com pacientes zika-SGB.

Ampla Especificidade de Gangliosídeos no Plasma de Pacientes com Zika-SGB

Dissecamos ainda os padrões de reatividade anti-gangliosídeos observados em pacientes infectados pelo zika com ou sem SGB. Uma análise detalhada da reatividade antigênica mostrou que os pacientes que desenvolveram a SGBreconheceramumnúmerosignificativamente maior de antígenos (gangliosídeo isolado ou combinado) em comparação com pacientes sem SGB (Figura 2A). O maior número de antígenos reconhecido foi encontrado em um paciente com SGB que reagiu significativamente a mais de 100 diferentes gangliosídeos isolados/combinações, enquanto todos os pacientes não-SGB reagiram significativamente contra 2 ou menos antígenos. Quando analisamos quais gangliosídeos específicos tinham uma reatividade aumentada nos pacientes infectados com zika (em forma única ou combinada), observamos uma ampla reatividade a diferentes gangliosídeos e outros glicolipídios (Figura 2B). Esses resultados sugerem uma ampla resposta aos anticorpos anti-gangliosídeos em pacientes zika-SGB, independente de combinações.

Isotipos de Anticorpos na Resposta AntiGangliosídica em Paciente Zika-SGB Altamente $\underline{\text { Responsivos }}$

Nosso rastreamento inicial de reatividade anti-gangliosídeos avaliou a presença total de anti IgM/IgG no plasma dos pacientes zikaSGB. Analisamos ainda as amostras para validar as respostas observadas em seis pacientes altamente responsivos, do grupo zika-SGB. Também dissecamos essa resposta determinando as reatividades IgM e IgG separadamente. Os resultados destes ensaios mostraram altos níveis de anti-gangliosídeos IgM e IgG nos plasmas desses pacientes comparados aos plasmas de controle. Além disso, esses ensaios validaram a forte e ampla reatividade do plasma de paciente com zika-SGB contra um alto número de gangliosídeos (Figura 2). Coletivamente, esses resultados confirmam a presença de anticorpos anti-gangliosídeos IgM e IgG no plasma de pacientes com zika-SGB. Nossos achados demonstram ampla reatividade a glicolipídeos com respostas mais fortes a gangliosídeos específicos. 
Figura 1. Reatividade de amostras de plasma de pacientes com zika com ou sem SGB.
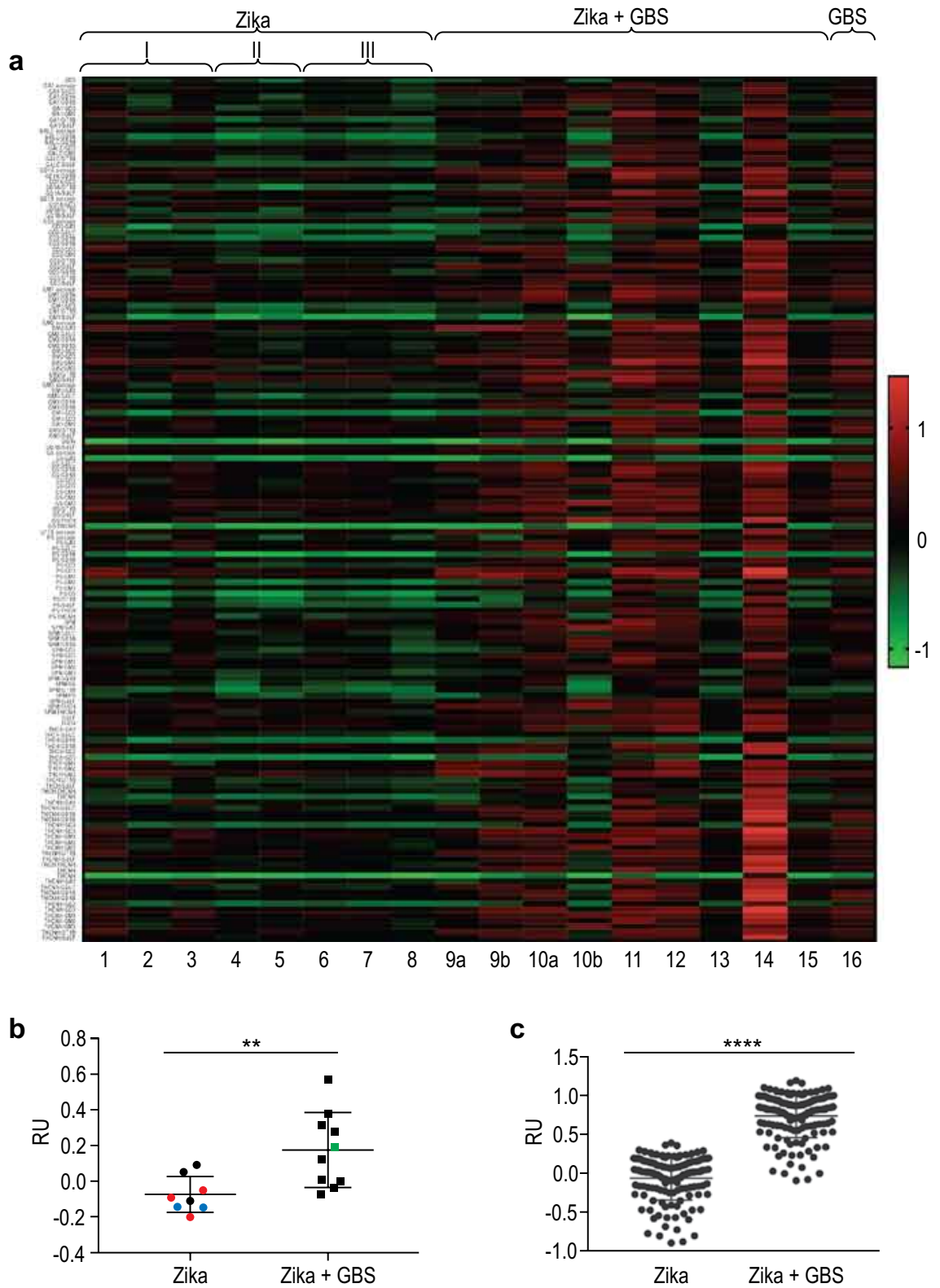

(a) Mapa de calor da reatividade do anticorpo alipídios únicos e combinações lipídicas. Resultados do plasma de pacientes com zika não complicado (aguda (I: pacientes 1 a 3) ou 4 meses após o início dos sintomas (II: pacientes 4-5), com infecção por zika e encefalite (III: pacientes 6-8), com infecção por zika e SGB (pacientes 9 a 15; a e b indicam diferentes momentos da amostragem para o mesmo paciente) ou com SGB de etiologia não identificada (paciente 16). Lipídios antigênicos utilizados: esfingomielina (SPM), fosfatidilserina (PS), sulfato (SULF), globosídeo (GS), tri-hexosilceramida (ácido graxo CTH-hidroxi) (THCH), tri-hexosilceramida (CTH) ácido graxo não hidroxi) (THCHN), galactocerebrosídeo (GALC) e os gangliosídeos GM1, GM2, GM3, GA1, GD1A, GD1B, GD2, GD3, GT1B e GQ1B.

(b) Média dos valores de reatividade para todos os lipídios e combinações em amostras depacientes com zika com ou sem SGB. Amostras de plasma de pacientes com zika agudo não complicado (preto4 meses após o início dos sintomas de uma infecção pelo zika (círculos azuis), zika com encefalite (círculos vermelhos) e zika com SGB (quadrados pretos). Uma amostra de plasma de um paciente com SGB, mas sem infecção por zika (não identificadaetiologia) (quadrado verde) não foi considerado na média.

(c) Média dos valores de reatividade para cada lipídeo e combinação lipídeos em amostras de pacientes com zika com ou sem SGB. Os dados são expressos como valores de RU. $p<0,05, p<0,01, p<0,001, p<0,0001$, quando os grupos são comparados entre si pelo teste t não-pareado. 
Figura 2. Análise antigênica da reatividade do plasma de pacientes com zika com ou sem SGB.
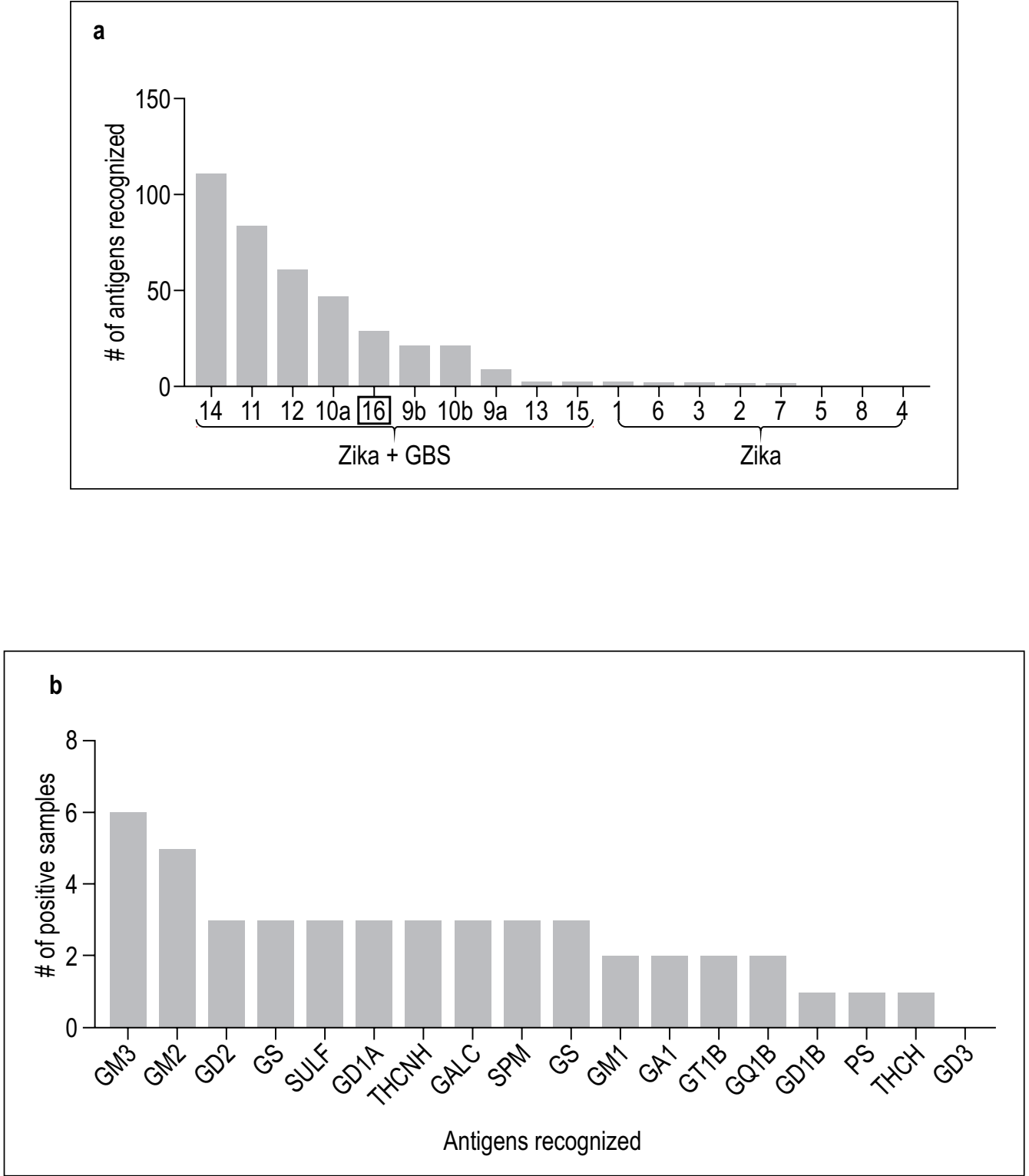

(a) Reatividade paraglicolipídios, apresentados de forma única ou combinada, das amostras de plasma de pacientes com zika (identificadas de 1 a 15; a eb indicam diferentes momentos no tempo de amostragem para o mesmo paciente). Paciente com SGB de etiologia desconhecida (16) está marcado com um retângulo vermelho. Os dados são apresentados como número de lipídios únicos ou combinações que foram reconhecidos poramostras de plasma de cada paciente. (b) Reatividade para glicolipídios únicos em amostras de plasma de pacientes com SGB associados ao zika (n=9) Uma amostra foi considerada positiva se seu valor fosse superior à média mais 3 três vezes o padrãodesvio dos valores obtidos para as oito amostras de pacientes com zika sem SGB. 


\section{Discussão}

Embora a infecção pelo vírus zika ter sido implicada no desenvolvimento de SGB, pouco se sabe sobre a patogênese dessa síndrome. Autoanticorpos diferentes foram identificados como mediadores de diversos distúrbios autoimunes, como anticorpos antinucleares no Lúpus eritematoso. De fato, a SGB é considerada uma síndrome autoimune devido à destruição imune de componentes nervosos periféricos, como gangliosídeos. ${ }^{8,9} \mathrm{~A}$ geração de anticorpos anti-gangliosídeos e outros autoanticorpos foram descritas em SGB induzida por infecção, tais como a uma clássica SGB induzida pela bactéria C. jejuni. ${ }^{6}$

Como os autoanticorpos anti-gangliosídeos estão implicados na patogênese da SGB, procurou-se determinar se os anticorpos antigangliosídeos estavam aumentados em pacientes zika-SGB em oposição aos controles infectados com zika com doença mais limitada.

Nossos resultados iniciais mostraram uma ampla e potente reatividade contra 17 diferentes gangliosídeos (isolados ou em combinação) mais frequentemente encontrados em pacientes zika-SGB. Esses anti-gangliosídeos eram ambos os isotipos IgM e IgG. Os anti-gangliosídeos $\operatorname{IgG}$ e IgM têm papeis patológicos sugeridos em SGB induzidos por infecção não relacionados ao zika.

Além do vírus zika, outras infecções por arbovírus, como dengue e chikungunya, também podem levar a autoimunidade e problemas neurológicos como a SGB.

Também avaliamos o plasma de dois pacientes com SGB com infecção ativa pelo vírus chikungunya e infecção prévia pelo zika $(\operatorname{IgG}+)$. Quando avaliamos o plasma desses pacientes quanto à reatividade aos gangliosídeos, nossos resultados demonstraram níveis de anticorpos anti-gangliosídeos significativamente menores que os pacientes com SGB com infecção ativa por zika. É possível que os anticorpos antigangliosídeos na circulação induzidos durante uma infecção por zika diminuam ao longo do tempo e não estejam mais presentes nesses pacientes. O papel de uma infecção ativa por chikungunya não é claro.

Os resultados sugeremque, emum subconjunto menor de pacientes infectados, a infecção pelo zika causa danos neuronais que desencadeia uma resposta autoimune de anticorpos contra antígenos gangliosídeos derivados de neurônios, o que contribui para a patogênese da SGB.

\section{Referências}

1. Duffy MR, Chen T-H, Hancock WT et al. Zika Virus Outbreak on Yap Island, Federated States of Micronesia. N Engl J Med. 2009;360(24):2536-2543. doi:10.1056/ NEJMoa0805715.

2. Cao-Lormeau V-M, Roche C, Teissier A, et al. Zika Virus, French Polynesia, South Pacific, 2013. Emerg Infect Dis. 2014;20(6):1084-1086.doi:10.3201/ eid2006.140138.

3. Ikejezie J, Shapiro CN, Kim J, et al. Zika Virus Transmission - Region of the Americas, May 15, 2015-December 15, 2016. MMWR Morb Mortal Wkly Rep. 2017;66(12):329-334. doi:10.15585/mmwr. mm6612a4.

4. Hoen B, Schaub B, Funk AL, et al. Pregnancy Outcomes after ZIKV Infection in French Territories in the Americas. N Engl J Med. 2018;378(11):985-994. doi:10.1056/NEJMoa1709481.

5. Goodfellow JA, Willison HJ. Guillain-Barré syndrome: a century of progress. Nat Rev Neurol. 2016;12(12):723731. doi:10.1038/nrneurol.2016.172

6. Godschalk PCR, Kuijf ML, Li J, et al. Structural characterization of Campylobacter jejuni lipooligosaccharide outer cores associated with GuillainBarré and Miller Fisher syndromes. Infect Immun. 2007;75(3):1245-1254. doi:10.1128/IAI.00872-06.

7. Sebastián UU, Ricardo AVA, Alvarez $\mathrm{BC}$, et al. Zika virus-induced neurological critical illness in Latin America: Severe Guillain-Barré Syndrome and encephalitis. J Crit Care. 2017;42:275-281. doi:10.1016/j.jcrc.2017.07.038.

8. Anaya J-M, Ramirez-Santana C, Salgado-Castaneda I, Chang C, Ansari A, Gershwin ME. Zika virus and neurologic autoimmunity: the putative role of gangliosides. BMC Med. 2016;14:49. doi:10.1186/ s12916-016-0601-y.

9. van der Meché FG, van Doorn PA. Guillain-Barré syndrome and chronic inflammatory demyelinating polyneuropathy: immune mechanisms and update on current therapies. Ann Neurol. 1995;37 Suppl 1:S1431. doi:10.1002/ana.410370704. 